\title{
Distribution of Customer Perception Information within the Supply Chain
}

\author{
Robert Schmitt \\ Laboratory for Machine Tools and Production Engineering WZL, RWTH Aachen University, Germany, \\ E-mail: r.schmitt@wzl.rwth-aachen.de \\ Bastian Quattelbaum \\ Laboratory for Machine Tools and Production Engineering WZL, RWTH Aachen University, Germany, \\ E-mail: b.quattelbaum@wzl.rwth-aachen.de \\ Björn Falk \\ Laboratory for Machine Tools and Production Engineering WZL, RWTH Aachen University, Germany, \\ E-mail: b.falk@wzl.rwth-aachen.de
}

\begin{abstract}
The purpose of the paper is the elicitation of customers' perception information regarding consumer goods within different levels of accuracy. In the industry for consumer goods many efforts are carried out for the elicitation of customer information, but a systematic preparation and distribution of the gathered information is missing. Information with different level of accuracy circulates within a company but is not centralized for corporate use. Based on a proposed holistic framework for objectifying customer information for supply chains' product specifications study procedures have been developed and corresponded studies were conducted. The results show that a gradual approach objectifies customers' perception. Products can be divided into subelements by identifying perception clusters and quality attributes. First correlations between customers' judgment and characteristics of quality attributes can be shown.
\end{abstract}

Keywords: : perceived quality, quality attributes, customer requirements, supply chain

\section{Introduction}

The market for consumer products is highly competitive. Offered products are technically excellent but are not able to differentiate themselves via performance features from each other. When comparing different products in the same industry, it becomes evident that, on the one hand, there is a narrow range of embodied technical features. On the other hand, there is an assimilation of technical product quality between products manufactured in classical high-wage countries and those in upcoming low-wage countries. These effects can be ascribed to the uncompromising concentration on process and technology improvements. That's why even a market leader has to detect new potentials for successful products. (Lüthi, 2006)

The key factor for the development of successful products is the customer. Companies have to gather a holistic set of information regarding their products from their customers. In order to be holistic, the set of information needs to contain performance and feature oriented requirements as well as subjective criteria like sensory quality perception. Additionally, it is essential to understand the influencing factors 
on customers' quality judgment such as brand image, price, or design. The future objective has to be the offer of high-quality products that are also perceived as high-quality by the customer. (Moss, 2006)

Companies and the whole Supply Chain have to focus on the customer quality perception, the socalled perceived quality. Without the knowledge of what most affects the customer and what he perceives as high quality and harmonious, the development and production of consumer goods is like a lottery. This is especially when considered against the background of the increasing number of system suppliers in the extensive value added chain.

The paper at hand will give an answer regarding the challenges of perceived quality. It shows that the customer is the preferred measuring device to gather comprehensive product requirements and describes methods for information elicitation. A systematic framework will be introduced to gather customer information regarding their product perception and disseminate it within the Supply Chain. Two case study results show the application of the presented framework.

\section{Challenges to Perceived Quality}

Due to the complex matter and interdisciplinarity of the topic, a common understanding of the term perceived quality is necessary. Numerous authors from different fields of research have designated their efforts to the field of customer perception. The majority of them deal with the identification of influences on the customer during his evaluation of products. These influences arise from both extrinsic and intrinsic quality cues of a product and its environment, including social, aesthetic, and functional aspects (Shapiro, 1970; Olson, 1972; Olson and Jacoby, 1972; Zeithaml, 1988; Steenkamp, 1989; Castleberry and McIntyre, 1992). The mostly theoretical nature of the models makes application in the product development process rather difficult. To industrialize the topic more manageable, Schmitt et al. (2008) define perceived quality as the result of the cognitive and emotional comparison of a customer's conscious and unconscious experiences, and thus expectations towards a product, and the actually realized product attributes in a specific use situation. This definition implicitly includes the customer's perception through his interdependent (Lindstrom, 2005) human senses.

Measuring perceived quality and the resultant perception of harmony demands an information source that provides holistic data about product requirements, both objective and subjective. It is indispensable for the product development process and the downstream production to define scales which offer a spectrum to describe the customers' product requirements in a detailed way. (Zalila et al., 2005) Available information sources are the common metrology for objective data, the assessment by product experts for a subjective-objective judgment and the customers' evaluation which procures subjective information. (Figure 1)

For a standardized and reproducible measurement, the application of metrology would fit best. But it is insufficient if the objective is to gather comprehensive information including subjective sensorial perception. Therefore, integration of human beings is still necessary. The input of product experts is important in later phases of the product development process, such as the specification phase. The definition of product specifications, including all objective and subjective requirements, is the experts' main task. The customer therefore is the main source for information elicitation regarding perception requirements. His information is highly subjective and difficult to survey but it is the key factor for successful products. Customers don't express their requirements comprehensively and not in ways which allow them to be used unfiltered and unprepared for the product

Figure. 1: Sources of Information

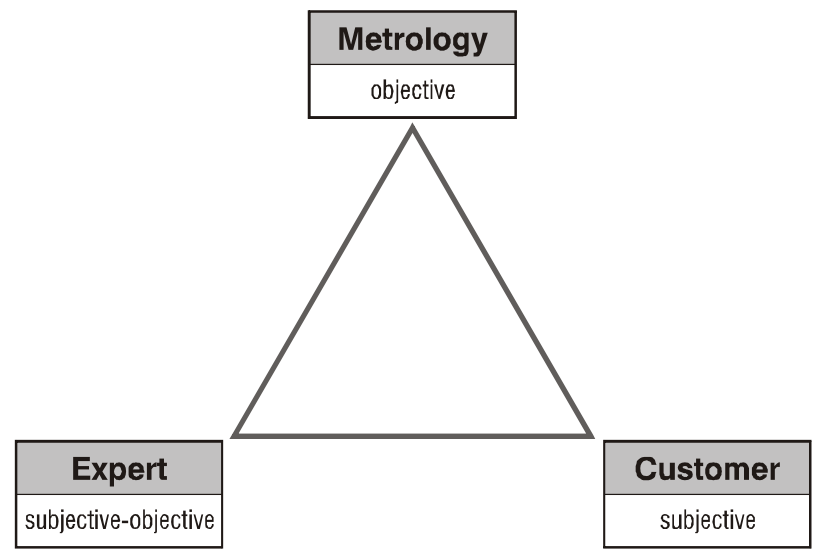


development process (Schmitt and Quattelbaum, 2009).

In research and industrial use there exist many methods to gather information of the different information sources, which try to link these with corresponding technical parameters (Yannou, 2004). In general, the recording of customers' expectations and requirements are on a high level of abstraction as a consequence of the lack of detailed technological product knowledge. This complicates the translation of the customers' information into specific product parameters and results in a misinterpretation process during product development. The elicitation and preparation of subjective and objective information is typically both cost- and time-intensive (van Hippel, 1994). In the following the different methods and their deficits will be described briefly.

The means-end approach addresses the personal-desire-complex and measures the functional and psychosocial consequences activated by the characteristics of products. Those consequences are the foundation (= means) for the realization of the overall individual desire imagination (= ends). (Reinicke, 2004) The main part of means-end is the "laddering"-approach, which gathers so called means-end-chains. A qualified interviewer tries to gather the probands' desires of relevant product characteristics with its implemented benefit for different customer-groups. The means-end approach lacks of a standardized procedure (especially the interviews) and most of the probands aren't aware of their personal values. (Lorenzi, 2003)

Lead-user workshops develop long-term customer requirements and trends. (Schröder et al., 1997) Lead-users are innovation-inspirer, who today have expectations regarding a product, which other customers aren't aware of. Based on technology trends the lead-users will be chosen, by checking if the probands already think in the direction of the trends or if they have own innovations for this topic. During different workshops the lead-users discuss possible problems of the new products, cluster them in fields of problems and develop problem-solving concepts. All in all the deficit of the lead-user method is the time-consummating, complicated and confirmed identification of lead-user-probands. (Gochermann, 2004)

In comparison to the lead-user workshops the concept tests are used for the integration of the customer in the product development process while interacting with a new product concept. Therefore the customers are confronted with new product designs visually or during interaction. Their opinions will be gathered with qualitative and quantitative survey methods. Concepts can be presented by photos, components, prototypes or pre-series products. Empirical results can be surveyed with proband groups from 500 - 1000 purchasers. (Schwarze, 2003) Concept test are cost-intensive and with the number of probands the danger for loosing product ideas to competitors increases. (Högl, 1996)

Supporting to the above mentioned methods kansei engineering translates proactive customer requirements, feelings and impressions regarding to existing products or concepts in new product concepts and parameters. (Schütte, 2004; Blecker, 2003) Therefore two multi-dimensional vector spaces are applied and connected with each other. The first space, the semantic space, offers for one superior product idea "kansei-words", which describe the idea with semantic word pairs. The second space, space of properties, includes all product properties, which have influence on the satisfaction of the customer. The connection of both spaces occurs by the description of each property with different kanseiwords. (Schütte, 2004) The specific problem with kansei-engineering is the reduction of the customer expression to the spoken words and the possible loss of necessary implicit requirements. (Schütte, 2004)

The conjoint-analysis aims on the evaluation of the customer benefit of a product by all important product characteristics. Therefore it is supposed that the overall benefit is the sum of the discrete benefit of the characteristics. (Eversheim, 2003; Dietz, 2000) From the frequency of characteristic mentions and the regarding product assessment the benefit of each component and characteristic can be inferred. (Eversheim, 2003) With increasing product complexity the number of characteristics influencing the overall judgement increases too and additionally the pre-definition of product characteristics by the company harbours danger because of a formative influencing. (Dietz, 2000)

The kano-method is most popular method for gathering customer requirements towards new products or improvements. It clusters the requirements regarding product characteristics into must-be, performance and attractive features. The 
fulfilment of these three clusters offers completely different levels of customer satisfaction. Kano, 1984; Löfgren, 2005) For the identification of the kanocluster the kano-survey is used. Probands are asked if they are satisfied when a product characteristic is fulfilled sufficient and when it is unsufficient. These two questions are asked during the kano-suvey for each product characteristic. With this pair of question an assignment to the kano-clusters can be applied. (Zultner and Mazur, 2006) The kano-model offers the possibility to cluster product characteristics, but is mostly feature driven and does not include the customers' sensorial perception. Additionally the subjective and unconscious character of customer requirements has to be handled (Tsiotsou, 2006).

One major problem of all methods is the establishment of "information islands" inside the organization. Instead of structured preparation and distribution of customer information, a great number of unlinked initiatives work with customers and the topic perceived quality. These different initiatives are spread over the whole product life cycle. The elicited information is in most cases used locally and thereby great potentials for a proper adjustment of the supply chain are wasted (Betzold et al., 2008).

\section{The Customer Requirements Bullwhip Effect}

Customer requirements and quality perceptions influence the internal production structure in a supply chain. Production is divided cross-company but its elements are aligned with each other. The management of this production is called flow oriented planning and is illustrated within value-adding chain diagrams. As a result of the divided production, interfaces occur where problems like miscommunication, duplication or nonspecific responsibilities exist. The supply chain management is responsible for the elimination of these problems as well as general improvements. (Ayers, 2000) Due to the high quantity of quality perception information and the new field of information, it is a new challenge for the information distribution within the supply chain. The reduction of costs and development time is a main objective in supply chains of consumer products (Erdmann, 2002; Arndt, 2006; Metz, 1998; Lambert and Cooper, 2000). Proper information about quality perception helps to reach this objective by focusing on parameters relevant to the customer and avoiding overengineering.

The so-called bullwhip effect is a vital problem of supply chain management and describes the difficulties of handling customer information within a value-added chain (Lee and Padmanabhan, 2004). Nowadays, the information distribution regarding perceived quality generally stops at the original equipment manufacturer (OEM) or the system supplier. The lower levels of the value-added chain hardly have knowledge about customer requirements. According to Vojak and Suárez-Núñez (2004) the information flow of perceived quality attributes forces a customer requirements bullwhip effect. The OEM gathers customer requirements about a product and its attributes. He interprets the requirements and specifies the quality attributes. At this moment the connection to the customer is lost for lower levels of the supply chain. They don't know the original statement of the customer and additionally there is no knowledge given which quality attributes interact with each other from the customers' point of view. Thus, the suppliers of lower supply chain levels have no idea with which other product components or quality attributes their products should fit together. This has the effect of a high amplitude of the bullwhip (Figure. 2).

Figure. 2: Customer Requirements Bullwhip Effect

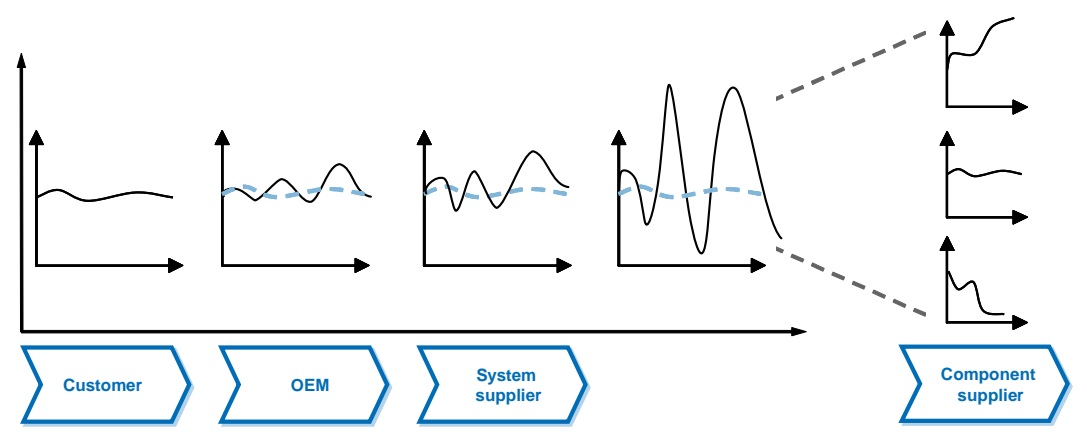


The customer requirements bullwhip effect shows the importance of holistic information distribution regarding perceived quality within the supply chain. For the reporting of technical and additionally perceived quality information even more information has to be handled. This is accompanied by a poor predictability. The factor perceived quality, the unconscious subjective requirements regarding the sensory perception, increases this poor predictability (Schmitt and Quattelbaum, 2009).

\section{Systematic Research Framework}

The integration of customers and their data in the supply chain has to be established. The research questions concerning the integration of customer perception data are:

1. How can customers be integrated in product assessments regarding perception?

2. Can customers deliver enough information without prior qualification?

3. Is the level of accuracy of this data sufficient for handling in a supply chain?

4. To which amount and information detail level has the customer to be integrated?

The concretization of the different research questions shows links between problems of practice and focuses on different research fields. Thus the central part of the scientific methodology is a heuristic framework (Kubicek, 1977). Components of this framework are the objects information elicitation, perception, customers, products and supply chain.
For safeguarding the production of attractive quality of products a five-stage framework according to Schmitt et al. (2009) for integrating perceived quality information into the product development is proposed. Figure 3 shows the proposed framework for objectifying customer information into the product specification. The framework is divided into five stages: Overall impression, perception cluster, quality attribute, descriptor and technical parameter. To achieve an improvement of attractive quality, detailed knowledge about the multi-sensory-perception of the product needs to be developed.

The first interaction of a customer with a product and the regarding impressions are reflected in the overall impression. Only to a small extent product details and individual components are the reasons for this impression. The overall impression is the foundation for analysis of a detailed multi-sensorial product perception. Taking factors like brand image, price or product harmony into account, no conclusions about the real causes of a customer judgment can be made by the overall impression (Macdonald, 2001).

Consecutively to the overall impression, as the first stage of accuracy, perception clusters encompass different product components that are perceived together as one unit, on the one hand through human sensory perception with one sense (e.g. tune of acoustic) and on the other hand on the level of superposition of senses (e.g. congruence in acoustics and haptics). For highly complex products like airplanes or cars the definition of perception clusters is essential to divide products into manageable areas

Figure. 3: Systematic Framework

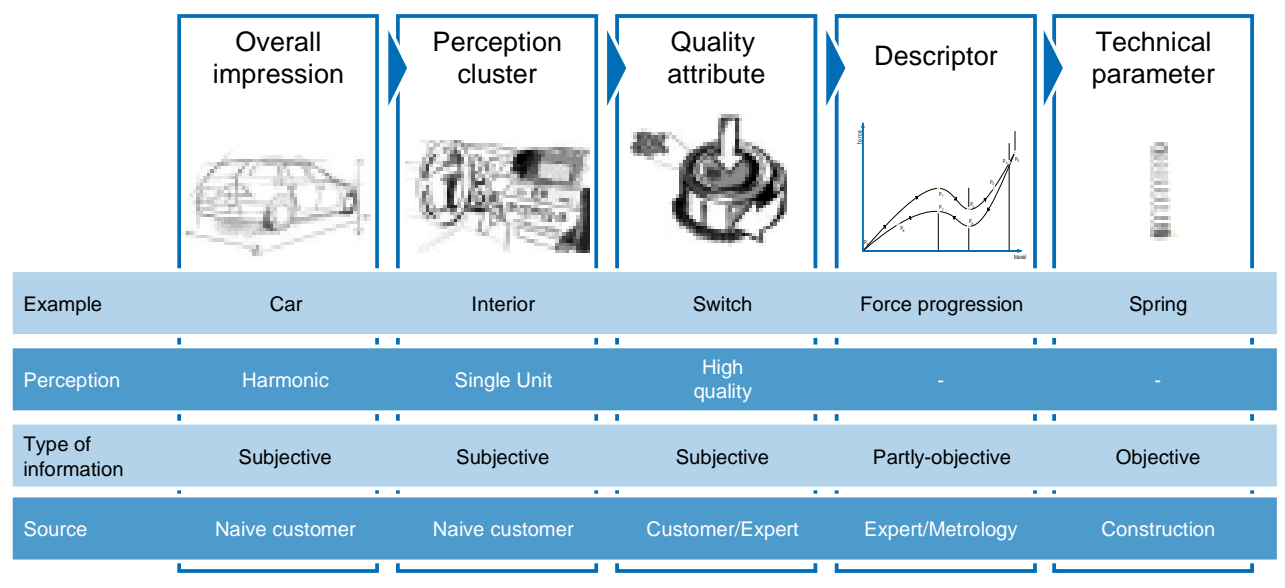


of interest. Perception mismatches within a cluster have negative influence on the customer cluster judgment and the overall impression.

The perceived quality of a perception cluster is determined by quality attributes. They have a strong influence on the overall quality judgment of a product and are represented by multi-sensorial product characteristics. The most important requirement to these attributes is the characteristic of scalability. If no scale for an attribute can be found, it still can be divided into sub-attributes (e.g. surface $\Rightarrow$ surface slippery). Overall the stage from perception clusters to quality attributes is the first detailing of a product regarding perception, which helps companies to avoid over-engineering and to focus on customer relevant product attributes.

The next stage of the framework is connected with a change in the data sources. Quality attributes are the last level of accuracy which can be an executed by naïve customers. Descriptors define a quality attribute in terms of "qualified" customers. For the definition of descriptors, which means objectifying attractive quality, "descriptive methods" derived from sensory analysis (Piper and Scharf, 2006) are necessary. During the application of these "descriptive methods" the customers describe their perception as specifically as possible while comparing quality attributes presented with different characteristic values. In this manner, quality attributes get described in the customers' vocabulary in a standardized way, correspondent with technical specifications to the greatest possible degree.

The last stage of the framework realizes the connection between the defined descriptors and technical parameters that are relevant for construction, production and installation. Consequently, the descriptors have to be measured by adequate and capable metrology. Not for each descriptor common metrology is available. New measurement methods and strategies have to be developed and validated. Companies, especially the construction and development departments, have to identify the set of technical parameters which impact on a specific descriptor. The activated effect for the customer can be stated by variation of the identified technical parameters combined with metrology. Beside the relationship between the customer judgments and the parameter variations for knowing a direction of product optimization, appropriate studies can elucidate the tolerance between a positive and a negative judgment for a certain quality attribute or descriptor. For industrial use, this point is far more interesting, because of knowing the range where to locate their product attributes.

The elicited information out of the presented framework has to be distributed throughout the whole supply chain and the prevalent isolated application of information without any systematic frame has to be replaced (Aslandis and Korell, 2003). The high number of interfaces within a company and throughout the supply chain have to be prepared to transport perceived quality information. Without defining the interfaces, an increased imprecision and data loss in processing would follow. Present approaches focus on snapshots for short term benefits and local improvements instead of a sustainable progress (Reinicke, 2004). In fact, the product specifications which are elaborated by the OEM are vague or become even more so while being passed on through different tiers of suppliers. This is caused by the pre-described misinterpretations of customer requirements and the missing tolerances when dealing with perceived quality data and leads to the mentioned "customer requirements bullwhip effect" (Schmitt and Quattelbaum, 2009). The stages of the framework in chapter 3.1 deliver information with different levels of accuracy about customers' perception. The long-term objective is the distribution of this information within the supply chain.

\section{Methodology}

The paper at hand focuses on the application of the framework stages perception clusters and quality attributes. Survey methods for gathering of conscious and unconscious information are:

- Free interviews,

- Observation during interaction,

- The "think-aloud"-method,

- Workshops in small-sized groups

- Empirical studies.

Free single interviews were chosen as method for the framework stage perception clusters. The decision against a standardized and automatically analyzable questionnaire was based upon the influencing character of this answering type. 
Customers should have the chance to express their own opinion and not with pre-formulated phrases. A combined observation by the interviewer as well as with different cameras allowed the retrospective examination of points of interest in the interview.

The "think-aloud"-method was used for both framework stages and can be applied in different settings. The range of settings can vary from presenting products by pictures, videos, sounds to the interaction with the real product. Probands express their associations and thoughts absolutely free and unfiltered, during being in contact with a product or an impulse. Besides the gathering of information about enthusing or frustrating product attributes, general knowledge about product handling and usability can be surveyed with the unfiltered expressions. The method represents the expressed thought-process sequentially and thereby facilitates the disclosure of causality within the customer's assessment procedure by the product developers. (Buber 2007)

For a successful application of the framework stage quality attributes a combination of different methods is suggested. A two step procedure for the survey of a comprehensive set of quality attributes is efficient. In the beginning the invited probands appoint quality attributes with the "think-aloud"method and discuss the defined personal attributes with all probands together in a moderated workshop. This workshop concept helps to discuss the different findings and negotiate a common active vocabulary. In a consecutive study with a larger number of probands the quality attributes can be evaluated empirically.

\section{Study Procedures, Participants, and Results}

\section{Cluster Identification Study}

The identification study for perception clusters was conducted by the example of a compact car interior. As the car interior is a complex part of the car the observation object was reduced to the front cabin (starting at the B-pillar), including driver and front passenger. The assessment focus was on haptical and optical perception.

The applied qualitative interview was a semistructured interview, divided into four main parts:
- Free interaction

- Binning components

- Interference analysis

- Target perception clusters

Opening, the probands were asked for a period of free interaction with the car interior. They had to articulate, applying the "think-aloud" method, their first expressions and opinions. In the second part of the interview, the probands defined which interior components belong together in their opinion concerning haptics and optics. They got accustomed to possible clusters and got an idea what binned components they like. With questions to the reasons of binning components, it was possible to get information what establishes a cluster from customers' point of view. Subsequently, the interview focused on interferences perceived by the probands. Defined interference were for instance caused by different colours, different topography between parts or clearances. Jointed with the customer judgment the stated interferences allowed a conclusion concerning which components should belong together to a cluster. Throughout the last interview part, the probands were asked to name their target perception cluster for a harmonious interior. In this part the interviewer reflected the before expressed clusters and interferences to secure the completeness of the cluster set.

The study was conducted in a defined, reproducible setting and lasted over two weeks, with approx. 14 time-slots per day. Beside written interviewer documentation, the study was documented by video and audio. In average 20 minutes lasting interviews 139 probands, aged between 18 and 60 years, were interviewed and recorded out of three camera perspectives. The sample size allowed differentiated analysis in nine evaluation groups. (Table 1) In analysis the customer expressed phrases were semantically clustered and the frequency of each cluster was evaluated.

Thereby seven main perception clusters (threshold $15 \%$ ) for the compact car were generated. Beside, for each cluster interface components were evaluated, which should fit harmonically to the cluster regarding optical and haptical perception. The seven analyzed main perception clusters were: (1) dashboard, (2) steering wheel incl. stalk switches, (3) gear box connected to hand brake, (4) instrument 
Table 1: Evaluation Groups

\begin{tabular}{|l|c|}
\hline \multicolumn{1}{|c|}{ Name of Group } & Participants \\
\hline Gender Male & 118 \\
Gender Female & 21 \\
Age "Young" (<29 years) & 107 \\
Age "Experienced" (> 28 years) & 32 \\
Car Type "Compact Car" & 48 \\
Car Type "Other" & 91 \\
Frequency of driving "seldom" & 91 \\
Frequency of driving "often" & 48 \\
Total participants & 139 \\
\hline
\end{tabular}

cluster panel, (5) doors, (6) footwell and (7) headliner.

The comparison of the nine evaluation groups showed a homogenous estimation of the analyzed seven perception clusters (Figure 4).

\section{Quality Attribute Study}

On the basis of the main perception clusters quality attributes have to be developed as the next stage of the proposed framework. Therefore a new study design according to the common approach of quality descriptive analysis out of the food industry sector was adapted and applied. This study design was used for the perception cluster "steering wheel". As observation object six different steering wheels from different classes of cars were presented. As mentioned in Chapter 4 the two steps of workshop and empirical study were employed. For the workshop on the one hand a wide demographic range of people had to be acquired and on the other hand only a few probands should participate out of time- and cost-consummating reasons. Twelve people in three different groups of age (18-30 years, 31-50 years and 51-70 years) were acquired. Each group included four probands, equally men and women. In the beginning the invited probands appoint quality attributes with the "think-aloud"method. The probands documented their personal quality attributes during interaction with the steering wheels in written form. Additionally to the written quality attributes they suggested a suitable scale for each attribute to secure the scalability. After this first step, the defined personal attributes were discussed by all probands in a moderated workshop. During this workshop the probands clustered their set of attributes, entitled these clusters with an attribute name and discussed and named adequate scales. As a result an agreed set of quality attributes and linked scales was defined, described in the language of the customers. The moderating experts learned, by participating and not influencing, the customers` active vocabulary. After this workshop a set of 44 quality attributes was available. With these 44 attributes the twelve probands assessed the six steering wheels. For each steering wheel all 44 attributes were characterized with the defined scale and the design was judged. In statistical analysis the 44 attributes were reduced to applicable an amount of attributes. Three reduction principles were used:

Figure. 4: Perception Clusters within Evaluation Groups

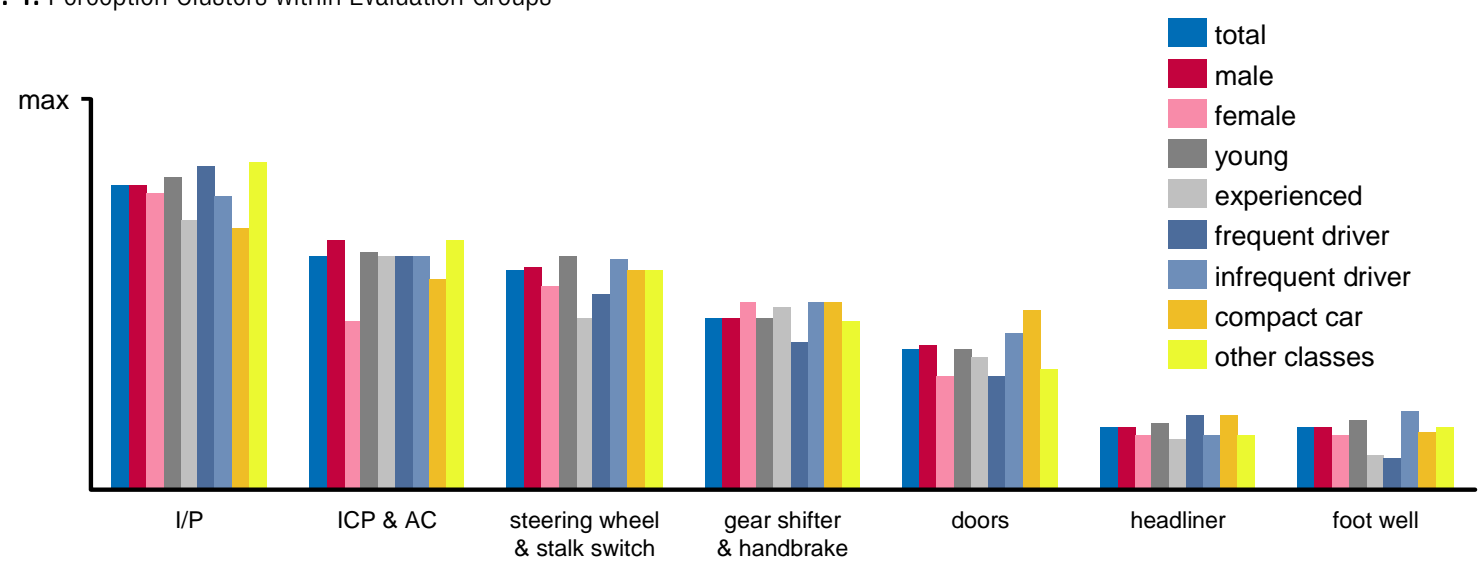


- Relation classes

- Standard deviation

- Rating Pareto

In a first analysis it was examined if all twelve probands related the steering wheel against each other in the same way. That means not to characterize the steering wheel equally, but to put them in the same relation. Secondly the normalized standard deviation of all probands for the different attributes was calculated and compared to a threshold of 0.7 . The normalized standard deviation stated compared to the relation classes how equally the probands characterized the steering wheels. At last the ranking of the probands where analysed with Pareto-method. The probands had the chance to assign 16 points to the 44 attributes to show their importance ranking. With the accumulated results the Pareto-analysis was applied. Following these three principles a reduction of the attributes to number of 26 attributes was possible, which were the attribute set for the consecutive empirical study.

This study was performed with 64 people, aged between 18 and 40 years. The objectives were the review of the identified quality attributes developed in the workshop and the assessment of the attributes for each steering wheel. Therefore the probands named in a short period of time quality attributes of the product. The set of attributes of all probands got compared with the workshop attributes. The degree of overlap determined if the defined quality attributes are sufficient to reflect the customers' mindset. The

Figure. 5: Reduction of Quality Attributes

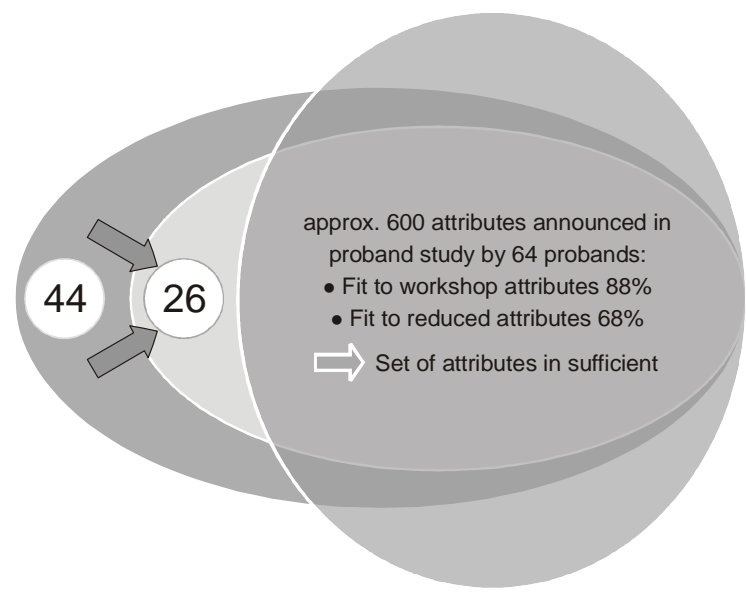

Table 2: Important Quality Attributes and their Impact

\begin{tabular}{|c|c|c|c|c|}
\hline Attributes & from 1 & to 6 & $\begin{array}{l}\text { Correlation- } \\
\text { Index }\end{array}$ & Country \\
\hline Clearance/Gaps & small & wide & 0,795 & small = good \\
\hline $\begin{array}{l}\text { Distance between } \\
\text { hand position and } \\
\text { switches }\end{array}$ & near & wide & 0,780 & near $=$ good \\
\hline $\begin{array}{l}\text { Haptical perceptibility } \\
\text { of switches }\end{array}$ & not perceptible & perceptible & $-0,754$ & $\begin{array}{c}\text { perceptible }= \\
\text { of good }\end{array}$ \\
\hline Material interfaces & smooth & rough & 0,711 & smooth $=$ good \\
\hline $\begin{array}{l}\text { Slippery of steering } \\
\text { wheel rim }\end{array}$ & no slippery & slippery & 0,615 & $\begin{array}{l}\text { no slippery = } \\
\text { good }\end{array}$ \\
\hline Size of visibility space & small & big & $-0,539$ & big $=$ good \\
\hline Protrusion of airbag & little & big & 0,526 & little = good \\
\hline Required force for horn & little & much & 0,510 & little $=$ good \\
\hline Visibility of stitching & not visible & visible & 0,080 & no significance \\
\hline $\begin{array}{l}\text { Surface roughness of } \\
\text { steering wheel rim }\end{array}$ & plain & rough & $-0,012$ & no significance \\
\hline
\end{tabular}

evaluated overlap was $68 \%$ compared to the 26 reduced attributes and $88 \%$ to the 44 general attributes (Figure 5). The overlap analysis was performed by comparing the announced attributes semantically.

Additionally the empirical study offered the chance to get a customer judgment for each quality attribute and the overall product. The probands were asked to fill a questionnaire-frontend where all scales for each attribute, visualized by a pictogram, were listed and to give the judgment with a 6 point Likert scale.

With these judgments correlation analysis between a quality attribute characteristic value and the direction of judgment were made, which is the foundation for specific product improvements. Ten of the 26 quality attributes showed significant (twosided significant level of 0.01 ) or no significant correlation between judgment and correlation with thresholds of 0.5 and 0.1 . For example the quality attribute "clearances/gaps" had the highest correlation index with 0.795 , which means small gaps lead to a positive judgment. In contrast for the attribute "visibility of stitching" no significance could be found. (Table 2) For the left 16 quality attributes further statistical analysis, like Structural-EquationModelling, is necessary to show interdependencies between the different attributes. 


\section{Conclusion and Forecast}

The presented paper shows an industrial framework to identify product relevant information of quality perception of the customer and gives instructions for the information distribution within the supply chain. However, the framework still holds room for adaption. Applying the framework through all five stages and in different branches of consumer products will advance its impact and prove its universality. Further studies for the application of the stage of quality attributes (e.g. with steering wheels and cordless phones) show that the descriptive methods adapted from the sensory analysis deliver very detailed and nearly objective information from the source "customer".

The usage of descriptive methods and the strong integration of the customer (qualifying them to experts), with a minimal focus on his product judgment, reduces the influence of social, functional and aesthetical aspects, such as brand image and design. Nevertheless, a consideration of these factors has to take place within the discussion on perceived product value (Schmitt and Steinmeier, 2008).

\section{References}

Arndt, H. (2006), Supply Chain Management. Optimierung logischer Prozesse, $3^{\text {rd }}$ Edition, Gabler Verlag, Wiesbaden.

Aslandis, S. and Korell, M. (2003), "Ihre Kunden wissen mehr als Sie!". io new management 72 (10), pp. 10-16.

Ayers, J. B. (2000), Handbook of Supply Chain Management, CRC Press, Boca Raton.

Betzold et al. (2008), Perceived Quality: Der nächste Evolutionsschritt der industriellen Produktgestaltung - Systematische, kosteneffiziente Gestaltung begeisternder Qualität. Wettbewerbsfaktor Produktionstechnik Aachener Perspektiven, Aachener Werkzeugmaschinen Kolloquium 2008, Apprimus Verlag, Aachen.

Blecker, T.; Abdelkafi, N.; Kaluza, B.; Friedrich, G. (2003), Variety Steering Concept for Mass Customization. Discussion Papers of the Institute of Business Administration at the University of Klagenfurt, p. 30.

Buber, R. (2007), Denke-Laut-Protokolle, in: Holzmüller, H. H. and Buber, B.: Qualitative Marktforschung: Konzepte-Methoden-Analysen, Gabler, Wiesbaden, pp. 557-565

Castleberry, S. and McIntyre, F. S. (1992), Consumers Quality Evaluation Process. The Journal of Applied Business Research 8 (3), pp. 74-82.
Dietz, W. (2000), Automobil-Marketing. Erfolgreiche StrategienPraxisorientierte Konzepte- Effektive Instrumente, mi, Landsberg/Lech, pp. 255-258.

Erdmann, M. K. (2002), Supply Chain Performance Measurement. Operative und strategische Management- und Controllingansätze, doctoral thesis, Universität Dortmund.

Eversheim, W. and Breuer, T. (2003), Methodenbeschreibung, in: Eversheim, W. (ed.), Innovationsmanagement für technische Produkte, Springer, Berlin, pp. 209-215.

Gochermann, J. (2004), Kundenorientierte Produktentwicklung. Marketingwissen für Ingenieure und Entwickler, Wiley, Weinheim, pp. 199-204.

Högl, S. (1996), Vom Reißbrett in die Köpfe der Verbraucher. Einsatz innovativer Marktforschung in der Automobilindustrie, in: Peren, F. W. and Hergeth, H. H. A., Customizing in der Weltautomobilindustrie, Campus, Frankfurt, pp. 295-296.

Kano, N.; Seraku, N.; Takashi, F.; Tsuji, S. (1984), Attractive Quality and Must-Be Quality. The Journal for Japansese Society for Quality Control 14 (2), pp. 166-188.

Kubicek, H. (1977): Heuristischer Bezugsrahmen und heuristisch angelegte Forschungsdesigns als Elemente einer Konstruktionsstrategie empirischer Forschung. in: Köhler, R., Empirisch und handlungstheoretische Forschungskonzeption in der Betriebswirtschaftslehre, Poeschel, Stuttgart, pp. 1-37.

Lambert, D. M. and Cooper, M. C. (2000), Issues in Supply Chain Management. Industrial Marketing Management 29 (3), pp. 65-83.

Lee, H. L. and Padmanabhan, S. W. (2004), Information Distortion in a Supply Chain: The Bullwhip Effect. Management Science 50 (12) pp. 1875-1886

Lindstrom, M. (2005), Brand Sense: Build Powerful Brands Through Touch, Taste, Smell, Sight and Sound, Free Press, New York.

Löfgren, M. and Wittel, L. (2005), Kano's Theory of Attractive Quality and Packaging. Quality Management Journal 12 (3), pp. 7-20.

Lorenzi, P. (2003), Entwicklung einer QualitätsmanagementMethode für die antizipative Kundenbedarfsanalyse, doctoral thesis, RWTH Aachen, Shaker, Aachen, 35ff.

Lüthi, E. (2006), Produkte in Bestform. Swiss Engineering (12/ 06), pp. 73-75.

Macdonald, A. S. (2001), Aesthetic intelligence: optimizing user-centered design. Journal for Engineering Design 10 (1), pp. 37-45.

Metz, P. (1998), Demystifying Supply Chain Management. Supply Chain Management Review 2(4), pp. 110.

Moss, C. (2006), Der Beitrag von Fertigungsstrategien zur Marktorientierung industrieller Unternehmen. Eine empirische Analyse im Rahmen des Projektes "International Manufacturing Strategy Survey", doctoral thesis, Mannheim. 
Olson, J. C. (1972), Cue Utilization in the Quality Perception Process: A cognitive Model and an Empirical Test, Unpublished doctoral dissertation, Purdue University, West Lafayette.

Olson, J. C. and Jacoby, J. (1972), Cue Utilization in the Quality Perception Process. Proceedings of the 3rd annual Convention of the Association for Consumer Research, College Park, pp. 167-179.

Piper, D. and Scharf, A. (2006), Descriptive Analysis - state of the art and recent developments, Forschungsforum, Göttingen.

Reinicke, S. (2004), Marketing Performance Management. Empirisches Fundament und Konzeption für ein integriertes Marketingkennzahlensystem, DUV, Wiesbaden, p. 187.

Reinicke, T. (2004), Möglichkeiten und Grenzen der Nutzerintegration in der Produktentwicklung. Eine Systematik zur Anpassung von Methoden zur Nutzerintegration, doctoral thesis, Technische Universität Berlin.

Schmitt, R. and Quattelbaum, B. (2009), Perceived Quality - New Information Data for Production Specifications. Conference Proceedings CAT2009, CIRP, Annecy, France.

Schmitt, R.; Quattelbaum, B.; Lieb, H (2008), Perceived Quality as a key factor for strategic change in product development. Conference Proceedings IEMC-Europe 2008, Piscataway, New Jersey, pp. 311-316.

Schmitt, R. and Steinmeier, B. (2008), Product Value Management. MQ Management und Qualität 4 (11), pp. 18-19.

Schröder, H.-H.; Zenz, A.; Schymetzki, G. (1997), Strategische Qualitätsplanung. In: Eversheim, W. Prozessorientiertes Qualitätscontrolling. Qualität messbar machen, Springer, Berlin.
Schütte, S. T. W.; Eklund, J.; Axelsson, J. R. C.; Nagamachi, M. (2004), Concepts, methods and tools in Kansei Engineering. Theoretical Issues in Ergonomics Science 5 (3), pp. 215-220.

Schwarze, J. (2003), Kundenorientiertes Qualitätsmanagement in der Automobilindustrie, Gabler, Wiesbaden, p. 245.

Shapiro, B.P. (1970), The effect of Price on Purchase Behaviour, Working Paper, Harvard University, Boston.

Steenkamp, J-B. E.M. (1989), Product Quality, $1^{\text {st }}$ Edition, Van Gorcum, Maastricht.

Vojak, B. A.; Suárez-Núñez, C. A. (2004), Product Attribute Bullwhip in the Technology - Planning Process and a Methodology to Reduce It. IEEE Transactions on Engineering Management 51 (3), pp. 288-299.

Tsiotsou, R. (2006), The role of perceived product quality and overall satisfaction on purchase intentions. International Journal of Consumer Studies 30, p. 210.

von Hippel, E. (1994), Sticky Information and the Locus of Problem Solving: Implication of Information. Management Science 40 (4), pp. 429-439.

Yannou, B. (2004), A methodology for integrating customers assessments during the conceptual design. Proceedings of the ASME Design Engineering Technical Conference, Salt Lake City, USA, pp. 7988.

Zalila, Z.; Guenand, A.; Lopez, J.M. (2005), Application of Experton Theory in the Sensory Analysis of Cell Phone Flaps. Quality Engineering 17(4), pp. 727-734.

Zeithaml, V. A. (1988), Consumers Perceptions of Price, Quality, and Value: A Conceptual Model and Synthesis of Research. Journal of Marketing 52(6), pp. 2-22.

Zultner, R. E.and Mazur G. H. (2006), The Kano Model: Recent Developments. The eighteenth Symposium of Quality Function Deployment, Austin, Texas, pp. 108-115.

Prof. Dr.-Ing. Robert Schmitt, born in 1961, is head of the Chair of Metrology and Quality Management and member of the board of directors for the Laboratory for Machine Tools and Production Engineering WZL of the RWTH Aachen University. He is also head of the department Production Metrology and Quality of the Fraunhofer Institute for Production Technology IPT as well as member of the board of directors of the Fraunhofer IPT.

Dipl.-Ing. Bastian Quattelbaum, born in 1979, is research assistant at the Chair of Metrology and Quality Management for the Laboratory for Machine Tools and Production Engineering WZL of the RWTH Aachen University. He is member of the research group "Perceived Quality and Product Value Management".

Dipl.-Ing. Dipl.-Wirt. Ing. Björn Falk, born in 1980, is research assistant at the Chair of Metrology and Quality Management for the Laboratory for Machine Tools and Production Engineering WZL of the RWTH Aachen University. He is member of the research group "Perceived Quality and Product Value Management". 